\title{
Caregiving to Family Members with Dementia
}

\author{
Laurie Wermuth \\ California State University, Chico
}

\begin{abstract}
The emotional and physical stress experienced by family caregivers of individuals with dementia is well known (Vitaliano, Jianping, Young, Caswell, Scanlan, Echeverria, 2009). Pearlin and colleagues (1990) noted that caregiving is complex, involving a variety of resources and strategies. The purpose of this qualitative study was to better understand careproviders' situations in context, including the resources they had available, the meaning of their care, and the strategies they employed to cope. Sixteen family care providers of adults with dementia were recruited through an adult services agency in northern California. Participants were interviewed using open-ended questions and the Center for Epidemiologic Studies-Depression scale (CES-D; Radloff, 1977). Field notes and interview transcripts for participants were interpreted, and compared with CES-D scores. Eleven out of sixteen care providers had scores indicating risk for clinical depression. Two groups are described: those with low distress scores, and those with high distress scores, highlighting some of the patterns associated with each. A list of coping strategies is provided from respondents' interviews. Based on the findings, community-based supports are needed to care for the increasing numbers of elderly individuals in the coming decades.
\end{abstract}

(C) 2011 Californian Journal of Health Promotion. All rights reserved.

Keywords: Alzheimer's disease, Dementia, Social support, Family issues

\section{Introduction}

\section{The Demographic and Policy Context of Caregiving}

The U.S. and other affluent countries have aging populations, with life expectancies moving upward by about three months a year. For example, in over just nineteen years, from 1980 to 1999 , forecasts of life expectancies for British males who reached the age of 60 increased by five years (CMI 2006; Dowd, Blake and Cairs, 2010). Better health has extended into the elder years, with disability decreasing among those over 65 in the U.S. (Manton and Gu, 2001). Growing numbers of older adults will require more medical and custodial care during their final years of life (Abel, 1990). As baby boomers age, there looms ahead what Ruth Rosen (2007) has called "a crisis of caring" with insufficient individuals and institutional supports available to provide care for the elderly, the sick, and the children of working parents. This paper presents results from a qualitative study of sixteen individuals who were providing care to a family member with cognitive impairment and memory loss. The purpose was to better understand the complexities of caring in home settings, and the strategies employed by caretakers.

\section{Background: Providing Care at Home in the U.S.}

Providing care at home is a widespread activity. A 2004 national survey found that nearly 23 million U.S. households included a caregiver of an adult family member or friend, and most often those caregivers are women (NAC \& AARP, 2004). Women provide the majority of all kinds of in-home care while also participating in the labor force in large numbers, creating increased pressures in their lives (Moen, Robison, \& Fields, 2000). Around 43 percent of the caregivers in the 2004 survey were over 50, and 13 percent were over 65 . Caregivers with lower incomes and less education tend to provide more help with everyday practical tasks; 
those with higher incomes and more education tend to purchase more services, and more often assist with managing finances (NAC \& AARP, 2004).

As the "baby boom" generation ages, increasing numbers of people will develop dementia and other forms of cognitive impairment (Plassman, Langa, McCammon, Fisher, Potter et al., 2011). Alzheimer's disease is estimated to grow to nearly 9 million individuals in North America by 2050 (Brookmeyer, Johnson, Ziegler-Graham \& Arrighi, 2007). Therefore, dementia is becoming an important public health issue and further development of services is required to address it (Georges, Jansen, Jackson, Meyrieux, Sadowska \& Selmes (2008). Dementia actually refers to a number of syndromes characterized by diverse behavioral, cognitive, and emotional impairments (Chapman, Williams, Strine, Anda, $\&$ Moore, 2006). In addition to these issues, supporting those individuals who are providing care deserves attention.

\section{The Stress, Coping, and Challenge of Caregiving}

Caring for a spouse who has a progressive form of dementia has been found to be stressful, to involve losses, and is associated with mental health problems, including depression (Vitaliano, Jianping, Young, Caswell, Scanlan, Echeverria, 2009; Adams \& Sanders, 2004; Bookwala, Yee, \& Schultz, 2000). An analysis of 84 studies comparing caregivers with noncaregivers concluded that caregivers were more stressed and depressed, with lower levels of subjective well-being, physical health and self-efficacy than noncaregivers (Pinquart \& Sorenson, 2003). Applying the stress process model revealed that primary stressors include behavioral problems and psychotic symptoms (Hooker, Bowman, Coehlo, Lim, Kaye, \& Guariglia, 2002; Shanks-McElroy \& Strobino, 2001; Whitlatch, Schur, Noelker, Ejaz, \& Looman., 2001; Schultz, 2000). Those who care for highly impaired individuals who behave in disturbing ways are likely to feel more burdened and depressed (Clyburn, Stones, Hadjistavropoulos, \& Toukko, 2000). Secondary stressors include the grief of slowly losing a loved one, and anticipation of the loved one's death (Meuser \& Marwitt, 2001). Prolonged duration of care, intensity of the care required, and conflicts with other responsibilities such as employment and family relationships also add stress (Chene, 2006; Biegel \& Schultz, 1999).

The ability of care providers to sustain care at home is related to factors beyond the severity of illness (Koerner \& Kenyon, 2007; Chene, 2006; Adams, Smyth, \& McClendon, 2005). Caretakers' tasks are varied and complex, extending beyond daily responsibilities to include financial stress, inability to fulfill role functions, complex negotiations regarding medical or social services, and deprivation of other family members' needs (Lefley, 1996). Caretakers also often feel alone in making the difficult decision to place their loved one in institutional care (Chene, 2006). For all these reasons, caregivers are at heightened risk for elevated stress hormones, suppressed immunity, ill health, depression, and impacts on employment and family relationships (Adams et al., 2005; Vitaliano, Zhang, \& Scanlan, 2003).

While stress may be viewed as a universal aspect of life, the stress that caregivers experience makes them vulnerable to emotional and physical harm. Hatfield's (1987) three variables for considering the effect of mental illness on the family align conceptually and empirically with evidence on caregiver stress and ability to continue in-home care. These include: (1) where the ill person lives and who is charged for responsibility for his or her care; (2) the meaning of the illness to the family and especially the way in which that meaning is influenced by prevailing theories of etiology; and (3) the degree of understanding, compassion, and support given to affected families and the skill and appropriateness of help offered by the community. Among family care providers, greater stress is associated with living with and being responsible for the elder person's care, experiencing the grief of watching them deteriorate over time, and inadequate supports from family, neighbors, community agencies, and governmental programs.

\section{Cultural and Interpersonal Meanings as Contexts of Caregiving}


Cultural meanings regarding caregiving, and also the perceived meaning of the relationship to the individuals involved, influence the emotional content of caring. These meanings, in turn, influence the emotional health of caregivers. For example, a study of African American caregivers observed that they appraised patient problems as less stressful, reported higher selfefficacy in managing problems, and experienced less depression compared to their White comparison group (Haley, Roth, Coleton, Ford, West, Collins, \& Isobe, 1996). Another study, of 94 family caregivers of individuals with dementia, found that the meaning and personal growth caregivers found in their experiences was associated with their persistence of caring (Farran, Keane-Hagerty, Salloway, Kupferer, \& Wilken, 1991). To complement larger studies, qualitative studies and case examples can provide insights into the following: the connections between social class/structural, life event, and chronic stressors that together influence the mental health of caregivers (Pearlin, 1989); detail regarding the variations and subjective aspects of caregiver stress (Lefley, 1996); and a view of coping strategies in the context of everyday life circumstances.

\section{Methods}

\section{Design}

This qualitative study utilized a measure of emotional stress, and in-depth interviews with adult caregivers. Participants were sixteen family members providing in-home care to older adults with dementia. The purpose was to gain insights into their emotional health, coping, and care management strategies. Participants were referred to the project by an adult resources center located in Northern California. Human Subjects review at the author's institution approved the study and signed consent was received from all participants.

\section{Instrumentation}

Two measures were used to elicit information from careproviders: 1) the 20-item Center for Epidemiologic Studies-Depression scale (CESD; Radloff, 1977), which measures a range of cognitive, affective, motivational and somatic symptoms in the general population; and 2) an interview schedule of 12 open-ended questions were asked of all participants. Follow-up questions asked for elaboration and clarification. Questions asked for information on the following: length of time providing care; an average day; the challenging and rewarding aspects of providing care; relationships with others involved; interactions/relationships with medical care providers; changes over time in providing care; coping strategies; whether there were people available to provide them support; medical diagnoses of the person receiving care; and what they would tell a person just beginning to provide this kind of care. A few demographic questions concluded the interview. Following each interview, the author wrote field notes that included impressions about the interviewee, others in the household, and the setting.

\section{Procedures}

All sixteen family care providers of individuals with dementia referred to the project agreed to be interviewed when contacted by the author. Interviews were conducted in participants' homes, except for two that were held in a coffee shop. Interviews were conducted from June to August of 2008. Interviews lasted from one-anda-half to three hours, depending on the length of participants' answers. The interview questions were asked uniformly and in order with each participant. Follow-up questions probed care providers' responses. With permission, all but one interview was audio taped. Interview field notes and transcripts were used to develop case descriptions for the respondents, focusing on sources of stress, available resources and social supports, coping, and care management strategies. Due to space limitations and to highlight the differences between those coping well and those coping poorly, the cases presented here are those with the five lowest and six highest CES-D scores. Interviewees were guaranteed confidentiality and pseudonyms are used in the case studies below.

\section{Participants}

Caregivers' relationships included eight wives, two husbands, four daughters, one son and one son-in-law. The ages of the sixteen care providers ranged from 51 to 88 years, with an average of 67.5 years old. The family members 
they were caring for ranged in age from 60 to 97 years, with an average age of 81.6. They had been providing care from 1.5 to 8 years, with an average of 3.75 years. All but one caregiver was White, reflecting the demographic makeup of the region. Yearly household incomes varied from $\$ 19$ thousand to $\$ 120$ thousand. Incomes could not be averaged due to the varied responses, including two who responded that their incomes "varied with the stock market".

\section{Results}

According to the CES-D scale, individuals scoring 16 or higher are considered at risk for clinical depression (Radloff, 1977). The CES-D scores of the 16 individuals in this study ranged from 3 to 35, with an overall average of 15.4. Eleven had scores over 16, from 19 to 35 with an average score of 28 in this more distressed group. The sixteen cases revealed a wide array of interconnected factors that influenced personal and practical adaptations and strategies. The interviews revealed that caregivers provided the kinds of personal assistance identified in the national caregiver survey (NAC \& AARP,
2004). They also included instrumental assistance such as managing outside care providers, finances, doctors' appointments, medications, shopping, housework, and other tasks.

\section{Coping Strategies}

When asked how they coped with caretaking, respondents described a variety of activities, including talking with friends and relatives, taking walks, and trying to find time to preserve some semblance of their own lives. Greater detail emerged when asked what advice they would have for others just beginning to provide care to a memory-impaired family member. Responses indicated caregivers' practical knowledge and emotional wisdom accumulated while providing care. They had learned about resources in the community as well as knowledge about doctors, medications, and equipment. Several had made physical adjustments to their homes, and some had addressed legal and financial issues required for managing their situations. Table 1 summarizes these. Additional details are in the case studies below.

Table 1

\section{Coping Strategies Identified by Careproviders}

- Identify a support network, and call or see these people regularly

- Develop watching and helping arrangements with neighbors

- Share rides with friends or use local public transit services (often Medicare approved) to doctors' appointments or social events

- Schedule children or volunteers for brief weekly visits to help with chores

- Discuss medications, their combinations, and side effects with pharmacists and doctors

- Find organizations for information and support regarding various forms of cognitive impairment, Alzheimer's disease, the older person's diagnoses and medications

- Use walkers, lift chairs, and installed poles as needed to prevent falls, and to prevent back and neck injuries to care providers

- When hiring helpers, require experience with cognitively-impaired individuals and, if needed, someone strong enough to assist the elder person in getting up and down safely

- Rely upon local or regional adult resource agencies for information and referrals to home health care agencies, institutional care facilities, and attorneys specializing in elder issues

Two groups of case descriptions are presented next. The first is the group of five care providers with the lowest distress scores. The second group includes six care providers with the highest distress scores. The case descriptions are developed from the in-depth interviews and 
observations made in their home settings. Occasional reference to CES-D responses are included as they appear relevant to the salient aspects of the careprovider's situation. The descriptions of Marian (with a low CES-D score) and George (high CES-D score) are longer than the others in order to describe patterns that are not typical in the literature.

Which Care Providers Are Doing Well?

The followng section and Table 2 describe five individuals with the lowest CES-D scores,

Table 2

Profile of Care Providers with Lower Scores on the CES-D Scale

\begin{tabular}{lcccccccc}
\hline Pseudonym & $\begin{array}{c}\text { CES-D } \\
\text { Score }\end{array}$ & $\begin{array}{c}\text { Relationship } \\
\text { to Elder }\end{array}$ & $\begin{array}{c}\text { Years } \\
\text { Providing } \\
\text { Care }\end{array}$ & $\begin{array}{c}\text { Stage of } \\
\text { Disease }\end{array}$ & $\begin{array}{c}\text { Age of } \\
\text { Care-giver }\end{array}$ & $\begin{array}{c}\text { Age of } \\
\text { Elder }\end{array}$ & $\begin{array}{c}\text { Household } \\
\text { Caregiver } \\
\text { Income } \\
\text { (yearly, in } \\
\text { thousands) }\end{array}$ & $\begin{array}{c}\text { Social } \\
\text { Support }\end{array}$ \\
\hline Nan & 3 & Daughter & 1.5 & Early & 56 & 87 & $\$ 120$ & High \\
Alice & 6 & Wife & 5 & Middle & 83 & 83 & $\$ 80$ & Medium \\
Jan & 11 & Wife & 5 & Middle & 60 & 60 & $\$ 80$ & Low \\
Richard & 12 & Husband & 1.5 & Advanced & 85 & 83 & $\$ 38$ & High \\
Marian & 13 & Wife & 2 & Middle & 73 & 74 & $\$ 19$ & High \\
\hline
\end{tabular}

ranging from 3 to 13 , indicating less vulnerability to depression. The summaries below focus on the salient aspects of each case as they pertain to their sources of stress, sources of support, and coping strategies.

\section{Nan: Managing mother's affairs}

Nan had the lowest CES-D score in the group. She worked full time, had her own family and a middle-class income. She did not live with her mother, but checked on her daily and coordinated her finances and doctors' appointments. Nan was distressed by her mother's combative behavior, and frustrated by her brothers' lack of participation in caring tasks. She described the following as helpful: going to workshops, listening to speakers, and being counseled by staff at the local elder services organization. Nan relayed that she became less distressed and more patient toward her mother as she learned more. She took over paying her mother's bills and stopped offering explanations or engaging in arguments. Nan enjoyed the social support of her sister-in-law, who shared in her mother's caretaking. They talked daily, supporting one another and making decisions together. Nan still found managing her mother's dementia and practical affairs challenging, but she was not distressed.

\section{Alice: Providing freedom within constraints}

Alice had been married to her husband for 35 years and still enjoyed his company. They were both 83, middle-class and financially secure. Alice continued to manage her own business interests and described herself as economically self-sufficient. Her goal was to maintain her husband's quality of life as long as possible. John did not admit he had a problem, forgetting that he had gotten lost many times and been in several car accidents. His license had been taken away, to the relief of his wife and children. According to Alice, the ability to go out in the car epitomized John's sense of control. He was contesting the loss of his license, but meanwhile, Alice and his neurologist were providing evidence to the Department of Motor Vehicles that he was unfit to drive. Alice shuttled around 
her husband since he frequently wanted to go out, preserving a sense of autonomy for him. John let Alice manage his medications.

Alice had social support from a group of women who meet regularly, and at the time of the interview, it was still safe to leave John for a few hours. In response to the question about feeling hopeful about the future, Alice responded, "most or all of the time."

\section{Jan: Managing dementia in middle age, but concerned for the future}

It took many months for Jan to realize that her husband had dementia, especially because he was only 55 when the symptoms emerged. Rob lost one job, then another, but declined to seek help. When Jan suggested they end the marriage, he agreed to go to a specialist where it was confirmed that he was experiencing a gradual decline in cognitive functioning. Jan worked full time and helped manage Rob's days by leaving notes and calling every couple hours. Jan reported that talking to staff at the local adult resources organization was a great help, but she was concerned that something bad might happen while she was at work. She was also afraid they could not financially manage his care in the future. They were a middle-class couple, but the need for daily care (which was quickly approaching) could cost them their house. Jan did not have a strong support network, but being employed and out of the home most of the day was helping her maintain her emotional health.

\section{Richard: Devoted care provider}

Richard's wife of 63 years was seriously disabled by a hip fracture that healed poorly. Lillian was confined to a wheelchair and also had advanced dementia. She was unable to speak, but Richard responded to her sounds and gestures. For several months he cared for her on his own, but the lifting became too difficult. While he continued to prepare meals, he brought in part time care providers and a house cleaner. Medicare paid for some in-home nursing care, and he could leave his wife alone for a few moments to take short walks. Their income is low, but because they own their home and because Richard is providing most of the care, their standard of living is closer to middle class.
Based on his wife's debilitated state and his age of 85, we might expect Richard to be distressed. Yet, he describes, "I don't consider this a burden. I'm just glad I can do it and I'm happy...we can still be together." Richard has support from the local adult resources agency, church members, friends and neighbors. He notes that his faith is "a real help."

\section{Marian: Constant companion and manager}

Marian cares for her visually impaired husband, Thomas, in the small home they own on a pleasant street. They are a low-income couple, relying on Social Security to pay their bills. They live very frugally, but financial pressures come from paying for medications. They are in their seventies and have been married 49 years. Marian and Thomas both have diabetes and she has cataracts developing. Marian used to accompany Thomas on his jobs tuning pianos, but with progressing dementia, Thomas had to stop working.

Marian expressed grief about the lack of contact from their sons. On the bright side, their daughter came by daily on her way home from work to help with chores. A volunteer also came by one hour each week. Marian and Thomas led an active social life. They belonged to several clubs with weekly or monthly gatherings and friends helped with transportation. Thomas's health at 74 was fairly stable, and he could still play the piano. Marian reports that he was sometimes disoriented, but felt reassured if she was nearby. Wandering was a bit of a problem, but he did not go far. They spent their time together, paying bills, testing their blood and taking medications, going to social events, and walking in the nearby park. Overall, Marian felt positive about their situation: "...We can take care of ourselves... and we can get around and do things."

From Marian's relatively poor health, meager resources, and nearly constant oversight of her husband, we might expect a high level of stress. However, her resourcefulness and active social life appeared to buffer against distress. Not only was she arranging rides, meals, and parties with their friends, she also astutely navigated her husband's medical care. She switched her 
husband's primary care physician because "they didn't weigh him or anything." She made sure he saw the urologist once a year to follow up on an earlier illness, and took him to the cardiologist every six months. With his primary care physician, she felt her husband's dementia was getting glossed over, so she wrote him a letter that prompted the doctor to introduce medication for Alzheimer's. A decline in Thomas or Marian's health in the coming years may disrupt their current routine. Until that time, Marian is likely to continue managing effectively.
Which Care Providers Are Doing Poorly? The six individuals described in Table 3 reported the poorest scores on the CES-D scale. A daughter and a son, both middle-aged, had mothers who had passed away a few months before the interview and were trying to get their lives back to feeling normal. Three wives were managing the demanding care of their husbands, feeling trapped and isolated. Their husbands had advanced dementia, and their relationships had changed dramatically. One husband, George, was still devoted and affectionate toward his wife, but experienced intense grief. All but one

Table 3

Profile of Care Providers with Higher Scores on the CES-D Scale

\begin{tabular}{lllllllll}
\hline Pseudonym & Score & $\begin{array}{l}\text { Relationship } \\
\text { to Elder }\end{array}$ & $\begin{array}{l}\text { Years } \\
\text { Providing } \\
\text { Care }\end{array}$ & $\begin{array}{l}\text { Stage of } \\
\text { Disease }\end{array}$ & $\begin{array}{l}\text { Age of } \\
\text { Caregiver }\end{array}$ & $\begin{array}{l}\text { Age of } \\
\text { Elder }\end{array}$ & $\begin{array}{l}\text { Caregiver } \\
\text { Household } \\
\text { Income }\end{array}$ & $\begin{array}{l}\text { Social } \\
\text { Support }\end{array}$ \\
\hline Jennifer & 35 & Wife & 2 & Advanced & 67 & 82 & $\$ 22 \mathrm{~K}$ & Low \\
Mary & 35 & Daughter & 5 & Deceased & 51 & 88 & $\begin{array}{l}\text { Middle- } \\
\text { class* }\end{array}$ & Medium \\
Amy & 31 & Wife & 5 & Advanced & 71 & 85 & $\$ 20 \mathrm{~K}$ & Low \\
Jack & 30 & Son & 3 & Deceased & 57 & 97 & $\begin{array}{l}\text { Low- } \\
\text { income** }\end{array}$ & Low \\
Helen & 28 & Wife & 5 & Middle & 82 & 84 & $\begin{array}{l}\text { Middle- } \\
\text { class** } \\
\text { Middle- } \\
\text { class** }\end{array}$ & Medium \\
George & 28 & Husband & 3 & Advanced & 88 & 89 & &
\end{tabular}

**

of these six caregivers lived with their elderly family member. Mary, whose mother had passed away, lived with her own family.

\section{Jennifer: Isolated by her husband's symptoms}

Jennifer's husband Bob suffered from frightening hallucinations of people and animals. This low-income couple was isolated in the foothills of the mountains. Bob sometimes threw furniture at the animals in his hallucinations, trying to scare them off. He stayed up much of the night, tormented by his visions, and he liked Jennifer to stay up with him to help keep him calm. Even during the day her sleep was interrupted by Bob's outbursts. There also is financial pressure; Social Security is their only source of income and the medications are expensive. No family members or close friends live nearby, but one neighbor sometimes helped them out. For support, Jennifer talked to her sister on the phone.

Jennifer provided around-the-clock care to make sure Bob did not hurt himself. He had fallen a few times over the past two years, and Jennifer injured her arms and shoulders trying to help him up. She described her biggest challenge as "keeping my sanity," and information from the local caregiver agency was helpful. Medications had not gotten the hallucinations under control, and Jennifer was distressed by their intensity. Bob's bizarre behavior kept them at home, and she could not leave him because no one else 
could care for him. "I'm in prison," she said, and she was also concerned about the future. "I'm 67 but I could still [die] first. What will happen to him? Because he's too active to be put in a home...they'd have to tie him down and medicate him really heavy...I know it's...going to get worse."

\section{Mary: Midlife disruption for mother's care}

Mary and her husband moved across the country with their two sons to take care of their aging parents. Her mother died a few months prior to the interview after five years of declining health. Her mother lived in assisted living for over a year before she passed away, the last five months in the dementia wing. Her mother's savings paid for the care. Mary described herself as recovering, including damage to disks in her neck from lifting her mother. Yet she regarded caring for her mother "an honor and a privilege" and "treasures" how close they were. Mary emphasized that her mother had vascular dementia, which caused less extreme cognitive impairment. Her mother was able to stay engaged socially, playing games and enjoying the company of Mary and her sons several hours a week.

\section{Amy: Burdened and isolated}

This was a second marriage for both Amy and Frank. They had a meager income but owned their mobile home in a mountain foothill community. Amy's husband Frank had dementia for five years and also Parkinson's disease. He used to do chores, but became disabled with his disease. His friends no longer called or visited. Frank got increasingly frustrated and angry, threatening and hitting Amy a few times. Medications got the aggressiveness under control and slowed the progression of his cognitive impairment. Amy no longer felt affectionate toward him, but believed she was doing the right thing by caring for him.

Amy wondered how much longer she could take care of Frank at home, but had mixed feelings about putting him in a care facility. His daughter, who lived out of state, wanted him to remain at home. They could not afford in-home care and Amy had already hurt her back trying to lift him. She purchased a lift chair for Frank and found "a lifeline" in the caregivers' group, where she went to meetings once a month. She also talked on the phone with members of her support group, a staff member, and her daughter.

\section{Jack: $24-7$ care for his mother}

Jack provided around-the-clock in-home care for his mother for the last three years of her life. He was unemployed at the time of the interview. He declined to indicate his mother's income, but said it was low. He expressed frustration more than once during the interview about not being able to afford help. His mother experienced chronic talking episodes that could go on for hours and into the night. His two daughters provided emotional support, and one did the weekly shopping. Jack did manage to hire a helper to come in three times a week to help his mother shower. Otherwise, he was at his mother's side. She would become fearful if he wasn't in her sight, and she had a buzzer to call him at night. Jack expressed feeling conflicted about the costs to his own life while providing care over the three years. He was glad that his mother was able to stay at home, and felt guilty contemplating putting her in a nursing home. The caregivers' support network helped him come to grips with those feelings, but he continued to feel disoriented about the direction of his own life.

\section{Helen: Community activist confined at home}

Helen managed her husband Martin's daily routine and medical care. She was 82 and he was 84 , and both were physically able and financially secure. This retired middle-class couple live in a beautiful home in a nice neighborhood. Helen could afford to hire more in-home help or place Martin in care, but had not yet found that necessary. Martin still enjoyed doing a few chores around the house with Helen's supervision. They continued to socialize with a few people that understood Martin's loss of short-term memory, and he was still able to play bridge.

Helen educated herself about Martin's condition and paid close attention to his diet, rest, medications, and appointments. The couple's two sons were encouraging Helen to put Martin into a nursing home, but Helen was reluctant 
because Martin clearly stated that he wanted to stay home. After 58 years of marriage, Helen's loyalty prevailed. "The fact is that he doesn't want to go...I can't drag him into the place and say, 'Here he is.' "'

In the past, Helen was active on several community boards and organizations, and she loved to exercise. She had dramatically curtailed her activities in order to care for her husband. When responding to the CES-D questions about feeling depressed, that everything is an effort, and being bothered by things, Helen said that she felt this way "most or all of the time." And to the statement about feeling hopeful about the future, she responded "rarely or none of the time."

\section{George: Devoted and grieving husband}

Barbara and George had been married for 68 years, and George had been caring for his wife at home for the past three years. They had a good income from investments and lived in a pleasant and friendly neighborhood. Barbara was confined to a wheel chair and had advanced dementia. Helen fell and fractured her hip a year and a half prior to the interview and it did not heal properly. George described that being immobile had led his wife to gain weight, which had made her care more difficult. His own health was good except for heart problems.

With a spacious home and financial resources, George had set up a system of daily care for Helen. Home health care workers arrived in three shifts from morning into the evening. He required they have experience working with individuals with dementia and be strong enough to help Helen move about. George had made many accommodations, such as adding poles for grabbing to prevent falls while his wife was getting up and down. George stated that he felt good about caring for his wife, but he also expressed grief witnessing her debilitation. He still loved her "desperately." While many people encouraged George to put Barbara in a nursing home, he was determined not to do so.

George and Barbara's three children did not live close by, but they talked on the phone. However, George was not isolated. He talked with their gardener every week, a good friend of many years. Several long time neighbors checked in, bringing food and offers to help. One neighbor had a key to the house, and they had a system of turning lights on and off at certain times to signal that all was well. George arranged this system knowing that he could have more heart problems. If the neighbor noticed irregularities, he would come in to check and call for help if needed. George grieved over the loss of the wife he knew, and did not look forward to life after she passed away.

\section{Discussion}

\section{Case Study Summary}

\section{Low distress caregivers}

Among the five caregivers with the lowest CESD scores, none felt trapped or isolated. Three had sufficient resources to employ help. Marian (caring for her sight-impaired husband) was resourceful, with a vibrant social life despite limited income. Jan, while currently working and managing her husband's care, was vulnerable to losing her home when her husband required care. This group generally had social support and were effectively managing their situations for the time being. They had considerable control over their daily lives and were deeply committed to their impaired family members.

In some respects Richard's (husband with some in-home help) experience was similar to Alice's (with her own resources and husband who liked to drive). Both couples had long marriages and an overriding desire to enhance their partners' quality of life. They realized that at present they could provide the best care possible at home. It is reasonable to interpret that the following factors contributed to their reported well being: their own efficacious management of their spouses' care; sources of social support, and their ability to purchase home health care services. In addition, these two cases remind us

that the meaning of providing care influences how emotionally challenging the job will be. Both expressed affection and devotion to their 
spouses, and satisfaction knowing they were providing the best quality of life possible. Richard especially had a demanding daily routine due to his wife's debilitated condition, yet he found ways to feel positive about caregiving.

\section{Distressed caregivers}

As a group, compared to the low-scoring group, these six caregivers shared the following: they were dealing with more severely disabled elders; overall they had weaker social supports; and they felt confined and trapped. For example, it is not hard to understand why Jennifer had a high distress score (35). Although she expressed compassion and commitment, she managed her husband's disturbing and aggressive behaviors with no respite. The partial exceptions to these three conditions include George, whose distress was caused by grief rather than feeling trapped, and Mary, the middle-aged daughter whose distress was also related to grief and finding direction in her own life following her mother's death. Mary's high score (35) may be more related to the disruption of her own life, including leaving her work and moving her family across the country. Her neck pain may also be taking its toll on her mood.

Amy's distress seems to require little interpretation beyond her own description: She is isolated and feels trapped in caring for her unkind and increasingly disabled husband. She is unable to lift him when he falls, and cannot afford help. She is uncertain about the future, and faces opposition from her husband's daughter regarding finding a care facility for Frank.

Like Mary, Jack was recovering from a long stretch of care providing in mid-life. His own life had been derailed, preventing him from having paid work and relationships beyond his immediate family. Helen was still focused on her own life and what she liked to do, unlike the other spouses interviewed. At 82, she was physically and cognitively able and energetic. Helen was a gregarious person who saw herself at the center of community life. She had studiously approached her husband's care and organized his daily life. Nonetheless, being confined to her home left her feeling isolated and unfulfilled.

George was somewhat of an anomaly: Despite having resources and social support, he was distressed. He had the resources to take breaks, but his affection and grief kept him vigilantly supervising his wife's care. He spared no expense to make sure his wife had the best care. He projected a solid sense of self and confidence in his management abilities, and was insightful in expressing his feelings of loss. We can interpret George's distress in terms of his grief and also his exhausting daily routine.

\section{Study Limitations}

From small qualitative studies we cannot draw general conclusions about larger populations. Also, since participants were referred by an adult resources agency, we do not know whether contact with this agency resulted in lower distress scores, or whether higher distress levels led them to seek help. Participants were interviewed at just one point in time; a series of interviews would have yielded a more full and accurate picture of their circumstances, coping, and emotional well-being. Finally, we do not know the participants' inclination toward depression prior to caregiving.

\section{Summary}

The case examples presented here illustrate the wide variety of factors influencing care-giving situations. They highlight the reality that although the patterns described in the literature guide our understanding of the conditions and stress of caregivers, they are not predictive of outcomes in particular cases. For example, George's case illustrates that, even in the presence of several factors conducive to emotional health, a caregiver may still feel depressed. Conversely, the case of Marian illustrates that even with meager financial resources, health problems, and weak institutional supports, a caregiver can be emotionally healthy and effective in managing her spouse's care. Marian's case does not conform to the finding that high vulnerability and fewer resources lead to greater caregiver burden and distress (Vitaliano et al., 2009; Vitaliano et al., 1991). However, the fact 
remains that as Marian and her husband grow older, they will not be able to sustain their lives without help.

Several of the factors that lead to caregiver distress are illustrated in the case examples presented here. These include: living with the individual; severity of condition; bizarre, disturbing or aggressive behaviors; lack of practical services and financial resources; and lack of social support. Financial resources for purchasing services, and institutional supports from community-based organizations, appear to be especially important. They can make the difference between a caregiver having hope versus despair in facing the future. Also, the meaning of providing care, and the relationship to the person with dementia, influences the caregiver's ability to cope with the situation. Consequently, the caregiver's grief is one of several factors influencing their emotional well being. For that reason, community-based services are important for providing emotional support.

Additional issues that surfaced in the case studies include the relative intensity and emotional content of the relationships as a factor influencing caregiver stress. It appears that greater intensity of affection may not prevent distress. The two husbands in decades-long marriages caring for severely disabled wives are examples: George's intensity of affection for his wife led to grief and depression, while Richard's did not. Also, the cases of Mary and Jack suggest that care giving during midlife poses some particular challenges. It may be that where employment, family, and geographic residence are disrupted, recovery from caregiving may be especially challenging. The case of Helen demonstrates that older individuals too may be deeply distressed by their lives being derailed by ailing spouses. It has been noted elsewhere that for young adult caregivers, it is important that they not be deterred from pursuing educational and career goals (Levine et al., 2005). In addition, male caregivers (young and old), when caring for older women, need assistance with personal care and in maintaining their own informal support systems (Levine, 2005; Sanders, 2007).

\section{Acknowledgements}

The author would like to thank Nancy Khanchandani, Passages Adult Resource Center in Chico, California, The Community of Caring, Cynthia Siemsen, Scott G. McNall, and four anonymous reviewers.

\section{References}

Abel. (1990). Family care of the frail elderly. In E. K. Abel \& M. Nelson (Eds.), Circles of care: Work and identity in women's lives (pp. 65-9 1). Albany: State University of New York Press., E. K

Adams, K.B., \& Sanders, S. (2004). Caregiver differences in experience of loss, grief reactions and depressive symptoms across the stages of Alzheimer's disease: A mixed methods analysis. Dementia: The International Journal of Social Research and Practice, 3(2), 193-208.

Adams, K.B., Smyth, K.A., \& McClendon, M.J. (2005). Psychosocial resources as moderators of the impact of spousal dementia caregiving on depression. Journal of Applied Gerontology, 24(5), 475-89.

Biegel, D.E. \& Schultz, R. (1999). Caregiving and caregiver interventions in aging and mental illness. Family Relations, 48(4), 345-54.

Bookwala, J., Yee, J.L., \& Schulz, R. (2000). Caregiving and detrimental mental and physical health outcomes. In G.M. Williamson, D.R. Shaffer, \& P.A. Parmelee (Eds.), Physical illness and depression in older adults: A handbook of theory, research and practice (pp. 93-131). New York: Kluwer Academic.

Brookmeyer, R., Johnson, E., Ziegler-Graham \& K. Arrighi, H.M. (2007). Forecasting the global burden of Alzheimer's disease. Alzheimer's \& Dementia 3: 186-191.

Chapman, D.P., Williams, S.M., Strine, T.W., Anda, R.F., \& Moore, M.J. (2006). Dementia and its implications for public health. Preventing Chronic Disease 3(2), 1-13. Available at: http://www.cdc.gove/pcd/issues/2006/apr/05_0167.htm. Accessed December 1, 2009. 
Chene, B. (2006). Dementia and residential placement: A view from the caregivers' perspective. Qualitative Social Work, 5, 187-215.

Clyburn, L.D., Stones, M.J., Hadjistavropoulos, T., \& Toukko, H. (2000). Predicting caregiver burden and depression in Alzheimer's disease. Journals of Gerontology Series B: Psychological Sciences and Social Sciences, 55(1), S2-13.

Dowd, K., Blake, D. \& Cairns, A. (2010). Facing up to uncertain life expectancy: The longevity of fan charts. Demography 47(1), 67-78.

Farran, C.J., Keane-Hagerty, S., Salloway, S., Kupferer, S., \& Wilken, C.S. (1991). Finding meaning: an alternative paradigm for Alzheimer's disease family caregivers. The Gerontologist, 31(4), 484-89.

Georges, J., Jansen, S., Jackson, J., Meyrieux, A., Sadowiska, A. \& Selmes, M. (2008). Alzheimer's disease in real life - the dementia carer's survey. International Journal of Geriatric Psychiatry $23,546-551$.

Haley, W.E., Roth, D.L., Coleton, M.I., Ford, G.R., West, C.A., Collins, R.P. \& Isobe, T.L. (1996). Appraisal, coping, and social support as mediators of well-being in black and white family caregivers of patients with Alzheimer's disease. Journal of Consulting and Clinical Psychology, 64(1), 121-29.

Hatfield, A.E. (1987). Families as caregivers: A historical perspective. In A.B. Hatfield and H.P. Lefley (Eds.), Families of the Mentally Ill: Coping and Adaptation (pp. 3-29). New York: Guilford.

Hooker, K., Bowman, S.R., Coehlo, D.P., Lim. S.R., Kaye, J., \& Guariglia, R. (2002). Behavioral Change in Persons with Dementia: Relationships with Mental and Physical Health in Caregivers. Journal of Gerontology: Psychological Sciences, 57B, 453-60.

Koerner, S.S. \& Kenyon, D.B. (2007). Understanding "good days" and "bad days": Emotional and physical reactivity among caregivers for elder relatives. Family Relations, 56 (January), 1-11.

Lefley, H. (1996). Family caregiving in mental illness. Thousand Oaks, CA: Sage.

Levine, C., Hunt, G., Halper, D., Hart, A.Y., Lautz, J., \& Gould, D.A. (2005). Young adult caregivers: A first look at an unstudied population. American Journal of Public Health, 95(11), 2071-75.

Manton, K.G. \& Gu, X. (2001, May 22). Changes in the prevalence of chronic disability in the United States black and nonblack population above age 65 from 1982 to 1999. Proceedings of the National Academy of Sciences, USA 98(11), 6354-9.

Meuser, T.M. \& Marwit, S.J. (2001). A comprehensive, stage-sensitive model of grief in dementia caregiving. The Gerontologist, 41(5), 658-72.

Moen, P., Robison, J., \& Fields, V. (2000). Women's work and caregiving roles: A life course approach. In E.P. Stoller and R.C. Gibson (Eds.), Worlds of difference: Inequality in the Aging Experience (pp. 165-175). Thousand Oaks, CA: Pine Forge/Sage.

National Alliance for Caregiving (NAC) \& AARP (2004). Caregiving in the U.S. Available at: http://www.caregiving.org/data/04finalreport.pdf. Accessed July 20, 2009.

Pearlin, L. (1989). The sociological study of stress. Journal of Health and Social Behavior, 30, 241-56.

Pinquart, M., \& Sorenson, S. (2003). Differences between caregivers and non-caregivers in psychological health and physical health: A meta-analysis. Psychology and Aging, 18, 250-267.

Plassman, B.L., Langa, K.M., McCammon, R.J., Fisher, G.G., Potter, G.G., Burke, J.R., Steffens, D.C., Foster, N.L., Giordani, B., Unverzagt, F.W., Welsh-Bohmer, K.A., Heeringa, S.G., Weir, D.R., \& Wallace, R.B. (2011). Incidence of dementia and cognitive impairment, not dementia in the United States. Annals of Neurology, Article first published online: 18 MAR 2011 | DOI: 10.1002/ana.22362 .

Radloff, L. (1977). The CES-D Scale: A self-report depression scale for research in the general population. Applied Psychological Measurement, 1, 385-410.

Rosen, R. (2007, March 12). The care crisis: How women are bearing the burden of a national emergency. The Nation, 11-16.

Sanders, S. (2007). Experience of rural male caregivers of older adults with their informal support networks. Journal of Gerontological Social Work, 49(4), 97-115. 
Schultz, R. (2000). Handbook on dementia caregiving: Evidence-based interventions for family caregivers. New York: Springer Publishing Company.

Shanks-McElroy, H.A. \& Strobino, J. (2001). Male caregivers of spouses with Alzheimer's disease: Risk factors and health status. American Journal of Alzheimer's Disease and Other Dementia, 16(3), 167-77.

Vitaliano, P., Jianping, Z., Young, H. M., Caswell, L., Scanlan, J., Echeverria, D. (2009). Depressed mood mediates decline in cognitive processing speed in caregivers. Gerontologist 49(1), 12-22.

Vitaliano, P.P., Russo, J., Young, H.M., \& Maiuro, R.D. (1991). Predictors of burden in spouse caregivers of individuals with Alzheimer's disease. Psychology of Aging, 6(3), 392-402.

Vitaliano, P.P., Zhang, J., \& Scanlan, J.M. (2003). Is caregiving hazardous to one's physical health? A meta-analysis. Psychological Bulletin, 129(6), 946-72.

Whitlatch, C.J., Schur, D., Noelker, L.S., Ejaz, F.K. \& Looman, W.J. (2001). The stress process of family caregiving in institutional settings. The Gerontologist, 41(4), 462-73.

\author{
Author Information \\ Laurie Wermuth, Ph.D.* \\ California State University, Chico \\ Department of Sociology \\ 400 West First Street \\ Chico, CA 95929-0445 \\ Phone: (530) 898-5691 \\ Fax: (530) 898-4571 \\ Email: 1wermuth@csuchico.edu \\ * corresponding author
}

